\title{
L'ANGOIO
}

appropriato, ma è frutto di un compromesso che tende a proteggere il rapporto medico paziente.

In questo senso alcuni esami (poco o per nulla invasivi come l'ecografia, l'ECG) sono prescritti più frequentemente ed in modo inappropriato rispetto ad altri, poiché soddisfano le attese dei pazienti, e sono ritenuti inoffensivi e poco costosi dai medici.

\section{Massimiliano Marinelli}

Bioeticista

Comitato Etico

Azienda Ospedaliera Universitaria

Ospedali Riuniti

Ancona

\section{PRESENTAZIONI}

\section{INFEZIONI OSPEDALIERE}

\author{
a cura di Marchiaro G. e Farina E. C. \\ Centro Scientifico Editore Torino, 2007
}

In un periodo di crescente emergenza dell'errore in medicina e di particolare attenzione al tema delle rischio di danno biologico in ospedale per pazienti ed operatori, questo testo di sobria fattura editoriale, può senz'altro essere annoverato tra i più interessanti della recente letteratura italiana sull'argomento.

In esso, medici, infermieri, microbiologi e farmacisti ospedalieri, ma anche manager e risk manager della sanità possono facilmente trovare aggiornate informazioni sul problema delle Infezioni ospedaliere, sulla sorveglianza, sul controllo e sul loro impatto economico.

Con il prezioso contributo di professionalità e di esperienza di numerosi autorevoli colleghi, come loro quotidianamente impegnati nella difficile gestione di que- sto serio problema dell'assistenza in importanti e complesse strutture ospedaliere del nostro Paese, gli Autori sono riusciti a realizzare un prezioso strumento, sintetico, di semplice consultazione e di sicuro riferimento operativo.

Non può essere sottaciuto, infine, l'interessante capitolo sui criteri di accreditamento per la prevenzione del rischio infettivo in ospedale ed il suo utile Manuale in appendice.

\section{MARCELLO M. D'ERRICO}

Professore Ordinario di Igiene Università Politecnica delle Marche Ancona

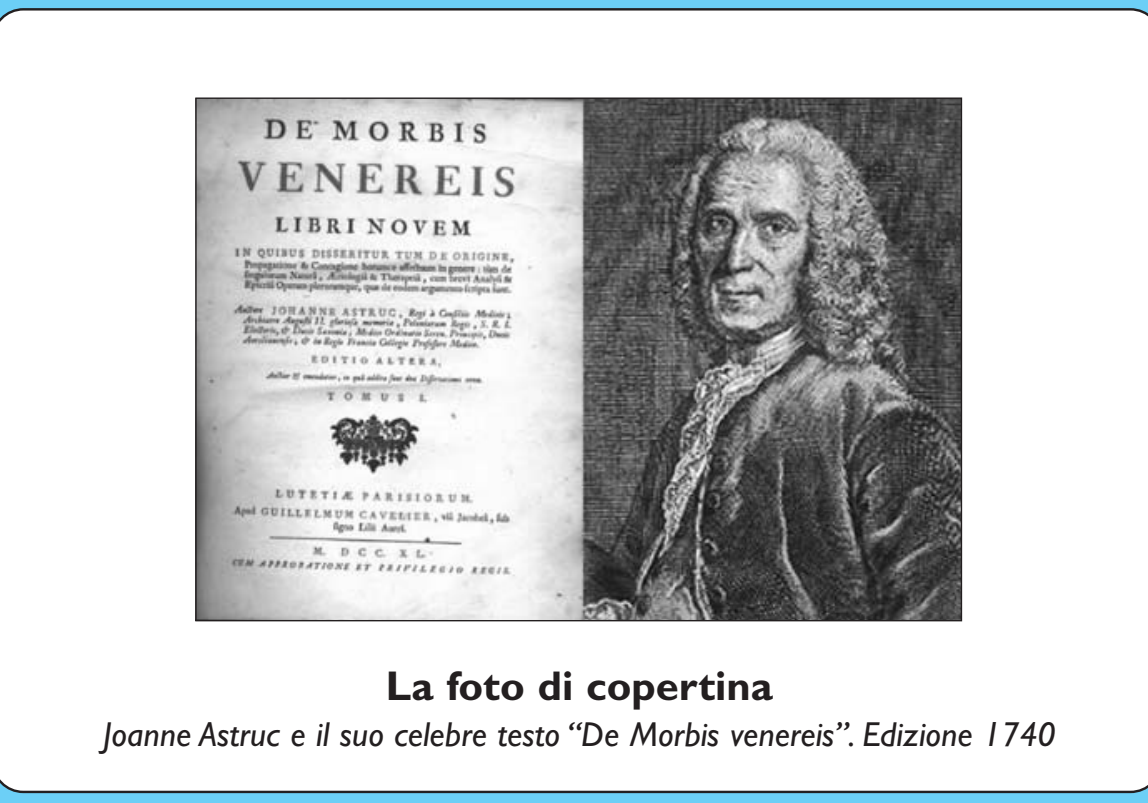

